J. Clin. Chem. Clin. Biochem.

Vol. 24, 1986, pp. 167-173

(C) 1986 Walter de Gruyter \& Co.

Berlin - New York

\title{
Eumelanin-Related Indolic Compounds in the Urine of Treated Melanoma Patients $^{1}$ )
}

\author{
By S. Pavel, H. Elzinga, F. A. J. Muskiet
}

Central Laboratory for Clinical Chemistry

Jitty M. Smit, N. H. Mulder

Division of Clinical Oncology, Department of Internal Medicine and

H. Schraffordt Koops

Division of Surgical Oncology, Department of Surgery

University Hospital Groningen, The Netherlands

(Received Juni 20/September 13, 1985)

Summary: A method was developed for the quantitation of six eumelanin-related indolic compounds in urine. The procedure employs methane ionization of the hexafluoroisopropyl and/or pentafluoropropionyl derivatives of 5,6-dihydroxyindole, 5-hydroxy-6-methoxyindole, 6-hydroxy-5-methoxyindole, 5-hydroxy-6methoxyindolyl-2-carboxylic acid, 6-hydroxy-5-methoxyindolyl-2-carboxylic acid and 5,6-dimethoxyindolyl2-carboxylic acid together with their deuterated analogues, and selected ion-monitoring. Deuterated analogues are added as internal standards to enzymatically hydrolysed urine before diethyl ether extraction.

The method was used for monitoring urinary excretion in patients with malignant melanoma treated with cytostatics. In several cases, a decrease of the excretion of the eumelanin-related substances was recorded after the therapy. The usefulness of the individual indolic compounds for such follow-up studies is discussed.

\section{Eumelanin-verwandte Indolverbindungen im Harn behandelter Melanompatienten}

Zusammenfassung: Eine Methode zur quantitativen Bestimmung von sechs Eumelanin-verwandten Indolverbindungen im Harn wurde erstellt. Das Verfahren verwendet die Methan-Ionisierung der Hexafluorisopropylund/oder Pentafluorpropionyl-Derivate von 5,6-Dihydroxyindol, 5-Hydroxy-6-methoxyindol, 6-Hydroxy-5methoxyindol, 5-Hydroxy-6-methoxyindolyl-2-carbonsäure, 6-Hydroxy-5-methoxyindolyl-2-carbonsäure und 5,6-Dimethoxyindọlyl-2-carbonsäure gemeinsam mit ihren deuterierten Analogen und Selected Ion Monitoring. Deuterierte Analoge wurden als interne Standards vor der Extraktion mit Diethylether nach enzymatischer Hydrolyse der Konjugate zum Harn zugefügt.

Die Methode wurde zur Überwachung der Ausscheidung der Verbindungen im Harn von cytostatisch behandelten Patienten mit malignem Melanom eingesetzt. In mehreren Fällen wurde nach der Therapie ein Abfall der Ausscheidung Eumelanin-verwandter Substanzen festgestellt. Die Brauchbarkeit der Bestimmung der einzelnen Indolverbindungen für solche Überwachungsstudien wird diskutiert.

1) Supported partly by the Koningin Wilhelmina Fonds (Netherlands Cancer Foundation) project No. 82-10 GUKC (S.P.)

J. Clin. Chem. Clin. Biochem./ Vol. 24, 1986 / No. 3 


\section{Introduction}

A well known problem in the management of cancer patients is the detection of the clinically occult changes of the disease. Different chemical approaches to these problems have been attempted, particularly in those tumours that exhibit characteristic biochemical features. Since malignant melanocytes usually synthesize melanin, it is not surprising that attention has been paid to the intermediates of the melanin synthesis and their determination in urine and serum of melanoma patients.

The attempts to use the pheomelanin precursor 5-Scysteinyl-DOPA as a tumour marker for malignant melanoma are well known $(1-3)$. Much less is known, however, about the possibility of employing eumelanin precursors and their metabolites (eumelanin-related compounds). This group consists of seven indolic substances:

\section{5,6-dihydroxyindole,}

5-hydroxy-6-methoxyindole,

6-hydroxy-5-methoxyindole,

5,6-dihydroxyindolyl-2-carboxylic acid,

5-hydroxy-6-methoxyindolyl-2-carboxylic acid, 6-hydroxy-5-methoxyindolyl-2-carboxylic acid and 5,6-dimethoxyindolyl-2-carboxylic acid.

Two of them, namely 5-hydroxy-6-methoxyindolyl-2carboxylic acid and 6-hydroxy-5-methoxyindolyl-2carboxylic acid, were identified by Duchon \& Matous in 1967 (4), the others were described during the last three years $(5-7)$.

Gas chromatography was shown to be a useful technique, providing good separation of the eumelaninrelated indolic compounds from urine of patients with malignant melanoma $(5,8)$. It failed, however, to detect the substances in urine samples of healthy persons, owing to their low concentrations and peak interferences with other compounds. Therefore a more selective technique of detection has been chosen.

In this paper we report our first experience with a gas chromatographic mass spectrometric method in chemical ionization mode, which has been used for follow-up of the urinary excretion of eumelanin-related indolic compounds in patients before, during and after cytostatic treatment.

\section{Materials and Methods}

Chemicals

Pentafluoropropionic anhydride and 1,1,1,3,3,3-hexafluoroisopropanol were purchased from Pierce Chemical Co., Rockford, IL, U.S. A., Helix pomatia juice was obtained from l'Industrie Biologique Française, Gennevilliers, France. 5,6-Dihydroxyin- dole, 5-hydroxy-6-methoxyindole, 6-hydroxy-5-methoxyindole, 5-hydroxy-6-methoxyindolyl-2-carboxylic acid, 6-hydroxy-5methoxyindolyl-2-carboxylic acid, 5,6-dimethoxyindolyl-2-carboxylic acid as well as their deuterium labelled analogues were prepared as described earlier (9). The compounds were stored as diluted ethyl acetate solutions at $-40^{\circ} \mathrm{C}$ under nitrogen, and their actual concentrations were measured shortly before their use by gas chromatography with a flame-ionization detector.

All other chemicals were purchased from Merck, Darmstadt, West Germany.

\section{Patients and treatment}

Brief descriptions of the individual cases of the melanoma patients are given in the legends to the figures.

All the patients were treated according to the following five day chemotherapeutic scheme:

days 1-4: (a) bleomycin $30 \mathrm{mg} /$ day in a continuous intravenous infusion

(b) dacarbazine $300 \mathrm{mg} / \mathrm{m}^{2}$ \& day intravenously

day 5 (a) vindesine $3 \mathrm{mg} / \mathrm{m}^{2}$ in an eight-hour infusion

(b) actinomycin $\mathrm{D} 2 \mathrm{mg} / \mathrm{m}^{2}$ in a half-hour infusion

To improve the alimentary conditions of the melanoma patients, $8400 \mathrm{~kJ} /$ day $(2000 \mathrm{kcal} /$ day $)$ in the form of Nutrison ${ }^{\circledR}$ (Nutricia Holland) were given for 25 days, starting 10 days before the cytostatic treatment.

\section{Samples}

Twenty four-hour specimens of urine were collected from melanoma patients and from healthy volunteers. Ten $\mathrm{ml}$ aliquots were then stored without any preservation at $-20^{\circ} \mathrm{C}$ until use.

\section{Hydrolysis, extraction and derivatization}

To $2 \mathrm{ml}$ of urine, $500 \mu \mathrm{l}$ of $2.5 \mathrm{~mol} / \mathrm{l}$ sodium acetate buffer $\mathrm{pH}$ 6.2 and $100 \mu \mathrm{l}$ of Helix pomatia juice were added. The solution was bubbled with nitrogen, the tubes tightly closed and placed in a shaking water bath at $37^{\circ} \mathrm{C}$ for $90 \mathrm{~min}$. To each hydrolysed urine sample, a mixture of home-made deuterium labelled indolic substances $(300 \mu \mathrm{l})$ was added, containing approximately 160 pmol 5,6-dihydroxyindole, 890 pmol 5-hydroxy-6-methoxyindole, 400 pmol 6-hydroxy-5-methoxyindole, 560 pmol 5-hydroxy-6-methoxyindolyl-2-carboxylic acid, 190 pmol 6-hydroxy-5-methoxyindolyl-2-carboxylic acid and 60 pmol 5,6-dimethoxyindolyl-2-carboxylic acid. The samples were saturated with $\mathrm{NaCl}$ and extracted with $2 \times 4 \mathrm{ml}$ of diethyl ether. Pooled extracts were dried over anhydrous sodium sulphate and evaporated to dryness at $40^{\circ} \mathrm{C}$ under a stream of nitrogen.

Derivatization was carried out by the addition of $50 \mu l$ of hexafluoroisopropanol followed by $100 \mu \mathrm{l}$ of pentafluoropropionic anhydride. The tubes were then heated in a heating block at $60^{\circ} \mathrm{C}$ for $10 \mathrm{~min}$. After evaporation under a stream of nitrogen, the residue was dissolved in $20 \mu \mathrm{l}$ of ethyl acetate containing $5 \%$ of pentafluoropropionic anhydride.

\section{Gas chromatography-mass spectrometry}

Gas chromatography-mass spectrometry was performed on a Varian 3700 gas chromatograph interfaced to a Varian MAT $44 \mathrm{~S}$ mass spectrometer with an open-split coupling. Data were recorded on a Varian MAT SS 200 data system. The gas chromatograph contained a $25 \mathrm{~m} \times 0.25 \mathrm{~mm}$ (i. d.) glass capillary column coated with SE-54 (Franzen Analysen-Technik, Bremen, West Germany). Injector temperature was set at $240^{\circ} \mathrm{C}$, interface temperature at $250^{\circ} \mathrm{C}$ and source temperature 
at $200^{\circ} \mathrm{C}$. Helium flow rate was $1.8 \mathrm{ml} / \mathrm{min}$ and ionization energy $180 \mathrm{eV}$. The oven temperature was programmed from 150 to $230^{\circ} \mathrm{C}$ at $10^{\circ} \mathrm{C} / \mathrm{min}$. The reagent gas (methane) pressure was $600 \mu$ bar.

\section{Quantification}

The concentration of the indolic compounds was obtained by calculating the peak-area ratios of the respective "pseudomolecular" $[\mathrm{M}+1]^{+}$ions of labelled and non-labelled compounds and comparing them to those obtained from known ratios plotted in calibration curves using linear regression analysis (PFP = pentafluoropropionyl, HFIP = hexafluoroisopropyl derivative, $-d_{0},-d_{2},-d_{4},-d_{5}=$ number of deuterium atoms in the molecule).

The following ions were monitored:

$\mathrm{m} / \mathrm{z} 588$ corresponding to the $[M+1]^{+}$of 5,6-dihydroxyindole(PFP) $)_{3}-d_{0}$

$\mathrm{m} / \mathrm{z} 590$ corresponding to the $[M+1]^{+}$of 5,6-dihydroxyindole(PFP) $)_{3}-d_{2}$

$\mathrm{m} / \mathrm{z} 456$ corresponding to the $[M+1]^{+}$of 5-hydroxy-6-methoxyindole(PFP) $)_{2}-\mathrm{d}_{0}$ and 6-hydroxy-5-methoxyindole(PFP) $)_{2}-\mathrm{d}_{0}$

$\mathrm{m} / \mathrm{z} 460$ corresponding to the $[M+1]^{+}$of 5-hydroxy-6-methoxyindole(PFP) ${ }_{2}-d_{4}$ and 6-hydroxy-5-methoxyindole(PFP) $)_{2}-\mathrm{d}_{4}$

$\mathrm{m} / \mathrm{z} 504$ corresponding to the $[\mathrm{M}+1]^{+}$of 5-hydroxy-6-methoxyindolyl-2-carboxylic acid(HFIP-PFP)- $\mathrm{d}_{0}$ and 6 hydroxy-5-methoxyindolyl-2-carboxylic acid(HFIPPFP) $-\mathrm{d}_{0}$

$\mathrm{m} / \mathrm{z} 509$ corresponding to the $[M+1]^{+}$of 5-hydroxy-6-methoxyindolyl-2-carboxylic acid(HFIP-PFP)-d $d_{5}$ and 6 hydroxy-5-methoxyindolyl-2-carboxylic acid(HFIPPFP)- $d_{s}$

$\mathrm{m} / \mathrm{z} 372$ corresponding to the $[M+1]^{+}$of 5,6-dimethoxyindolyl-2-carboxylic acid(HFIP)-d $\mathrm{d}_{0}$

$\mathrm{m} / \mathrm{z} 380$ corresponding to the $[M+1]^{+}$of 5,6-dimethoxyindolyl-2-carboxylic acid(HFIP)- $\mathrm{d}_{8}$

The position of deuterium atoms in the indole molecules was described earlier (9).

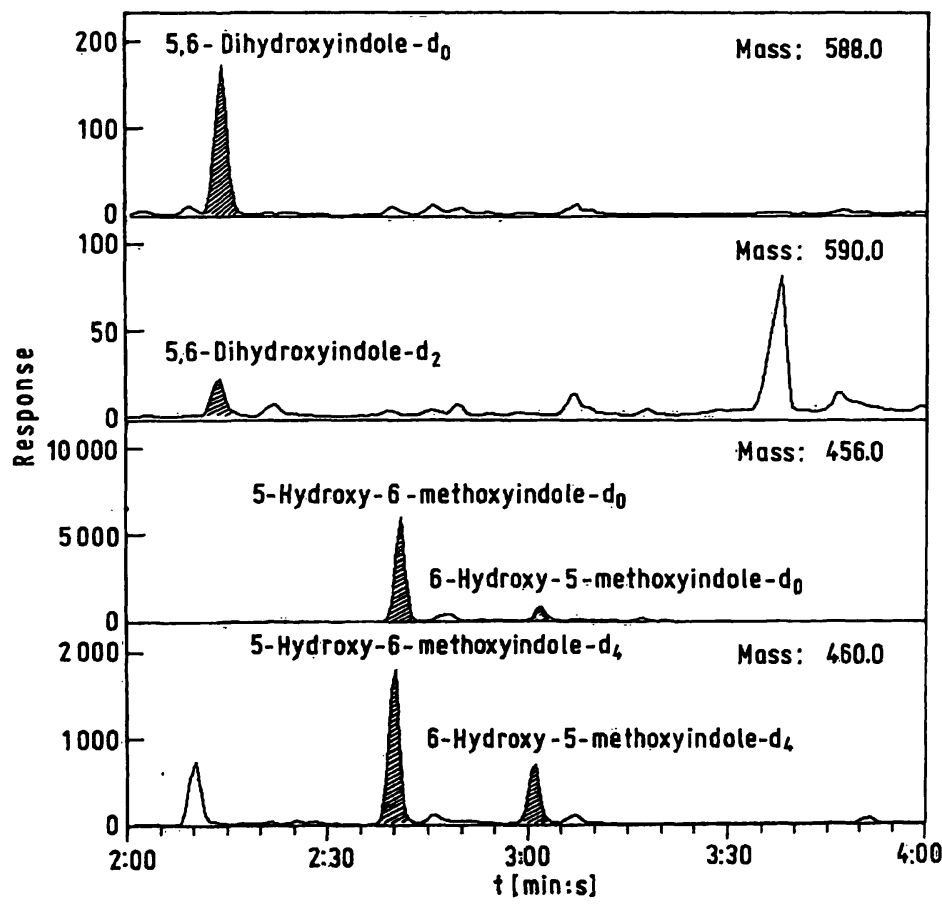

\section{Results}

As shown in figure 1, the method used gave a good separation of all eumelanin-related indolic compounds, which could therefore be measured in a single chromatographic run. The concentration of each substance was calculated by using its own internal standard and calibration curve. In the concentration range of $0.25-25 \mathrm{nmol} / 1$, the coefficient of variation of the method was satisfactory $(2.5-6.0 \%)$. However, when normal urine samples and those containing extreme concentrations of indoles were analysed, the coefficient of variation was found to be higher than $10 \%$. In the latter case, quality control could be improved by prior dilution of urine. The recoveries of individual indolic eumelanin-related compounds added to urine samples before their processing were in the range of $80-120 \%$.

The excretion values of indolic eumelanin-related compounds in four melanoma patients before, during and after the therapy are shown in figures $2-5$.

\section{Discussion}

Although the group of eumelanin-related indolic sub- . stances consists of seven indolic compounds, it appears that not all of them are suitable for routine laboratory determination. In general, the main eumelanin precursors, namely 5,6-dihydroxyindole and 5,6-dihydroxyindolyl-2-carboxylic acid, are known to

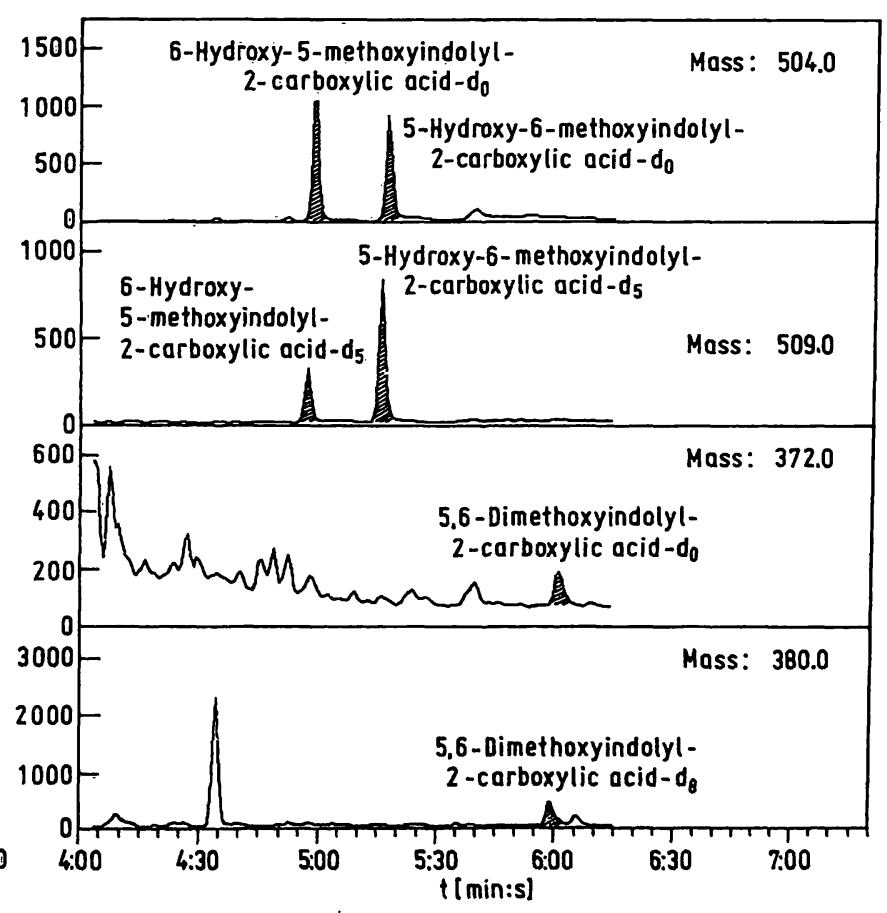

Fig. 1. Mass fragmentograms obtained from a derivatized extract of melanotic urine to which deuterated internal standards were added.

J. Clin. Chem. Clin. Biochem. / Vol. 24, 1986 / No. 3 

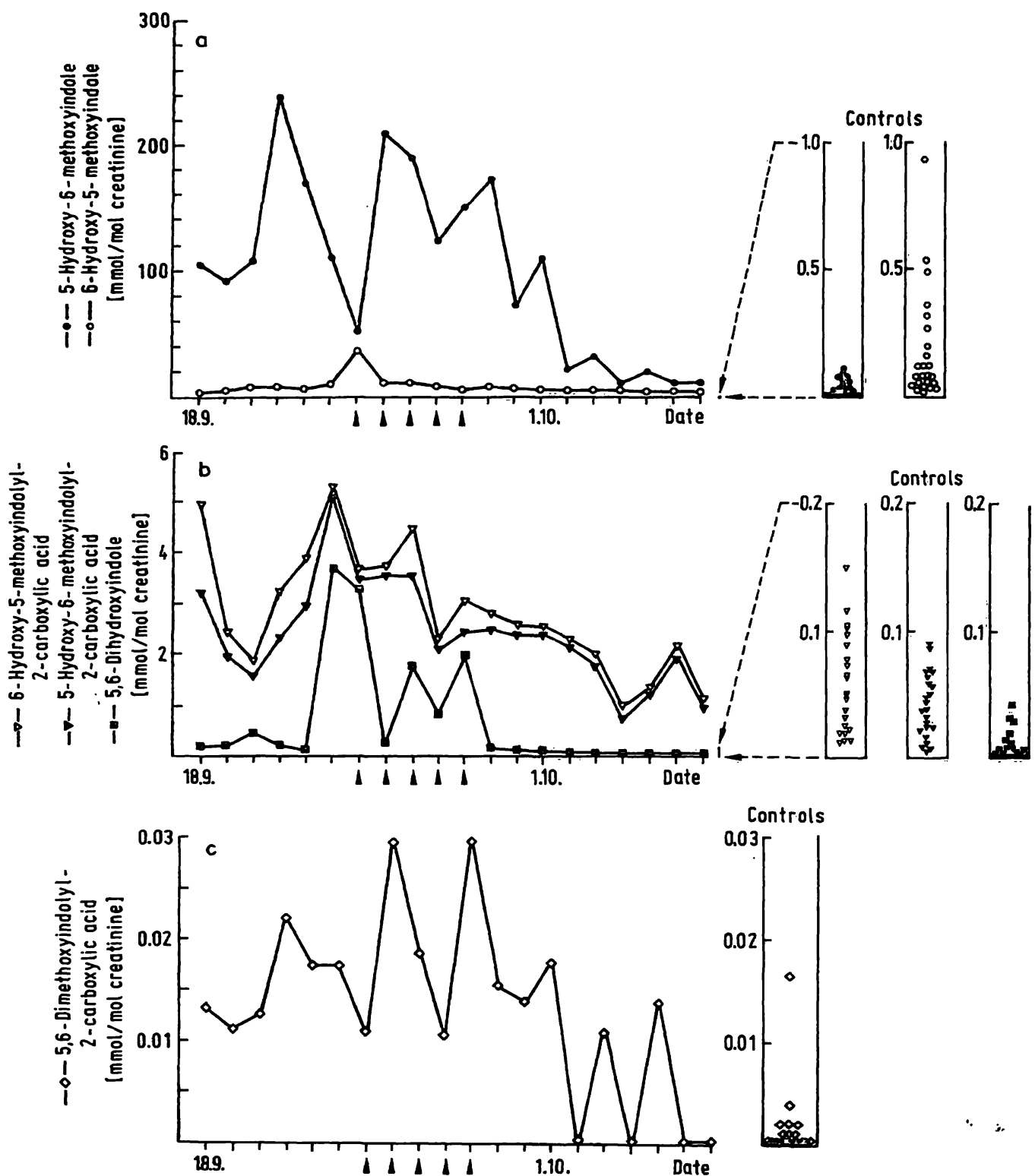

Fig. $2 \mathrm{a}-\mathrm{c}$. The urinary excretion of six eumelanin-related compounds by patient $\mathrm{K}$., a woman aged 59 , admitted with diagnosis subungual melanoma. Treatment: surgical. In August 1982, generalization of the process with high tumour burden (pulmonary metastases). The arrows indicate the days of the treatment.

readily undergo oxidation and polymerization. Their O-methylation and/or conjugation with sulphate or glucuronate at least partly protect them against the mentioned processes. However, our experience has shown that 5,6-dihydroxyindolyl-2-carboxylic acid is excreted in an unconjugated form and may therefore initiate secondary formation of melanin in melanotic urine during collection and storage. That is why the measured concentration of this substance in urine may not be related solely to its production rate, but may also be dependent on other conditions, such as $\mathrm{pH}$ of the urine or the presence of oxidative or reductive substances. In other words, the instability of this eumelanin precursor would make the interpretation of its concentration values unreliable. That was the reason why 5,6-dihydroxyindolyl-2-carboxylic acid was not included in our measurements.
Although 5,6-dihydroxyindole is reported to be excreted as a sulphate conjugate (10), and thus partially protected against polymerization and oxidation, its determination is accompanied by several structurally related difficulties:

(a) the compound is partially oxidized and polymerized during the hydrolysis,

(b) a small difference in the masses of the deuterated $\left(d_{2}\right)$ and natural $\left(d_{0}\right)$ analog causes partial quantitative overlap of measured ions and results in a nonlinear calibration curve, and

(c) the instability of deuterated and non-deuterated 5,6-dihydroxyindole during storage of the standard solutions used for calibration and standard addition. 

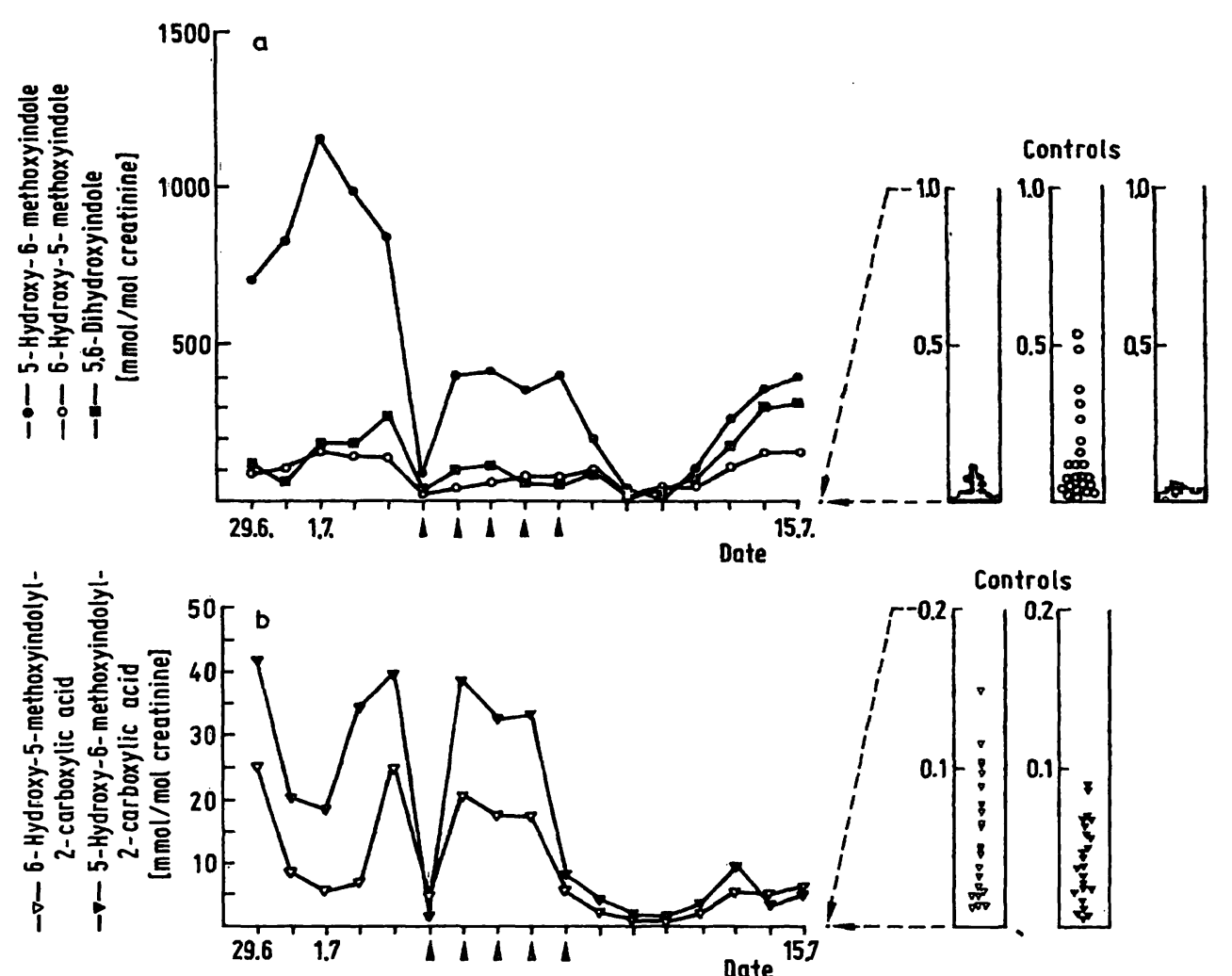

Fig. $3 \mathrm{a}-$ b. The urinary excretion of four eumelanin-related compounds by patient St., a woman aged 24, admitted with diagnosis skin melanoma (shoulder + lymph. nodes). Treatment: surgical and immunotherapy. In April 1981, generalization of the tumour with high tumour burden (pulmonary metastases). The arrows indicate the days of the treatment.
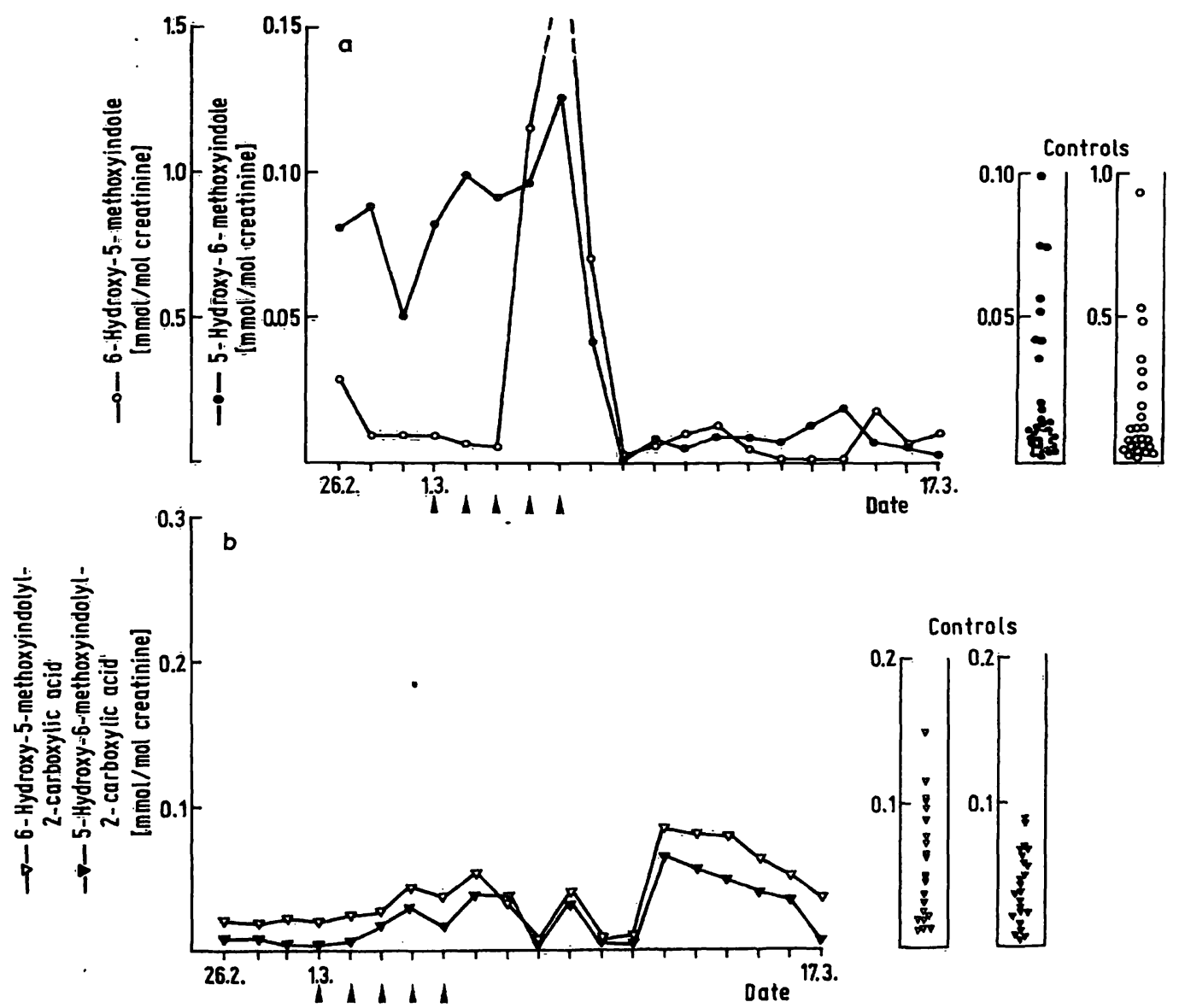

Fig. $4 \mathrm{a}-$ b. The urinary excretion of four eumelanin-related compounds by patient Si., a man aged 38 , admitted with diagnosis skin melanoma (the back side of the trunk). Treatment: surgical. In February 1982, tumour progression with low tumour burden (pulmonary metastases). The arrows indicate the days of the treatment. 

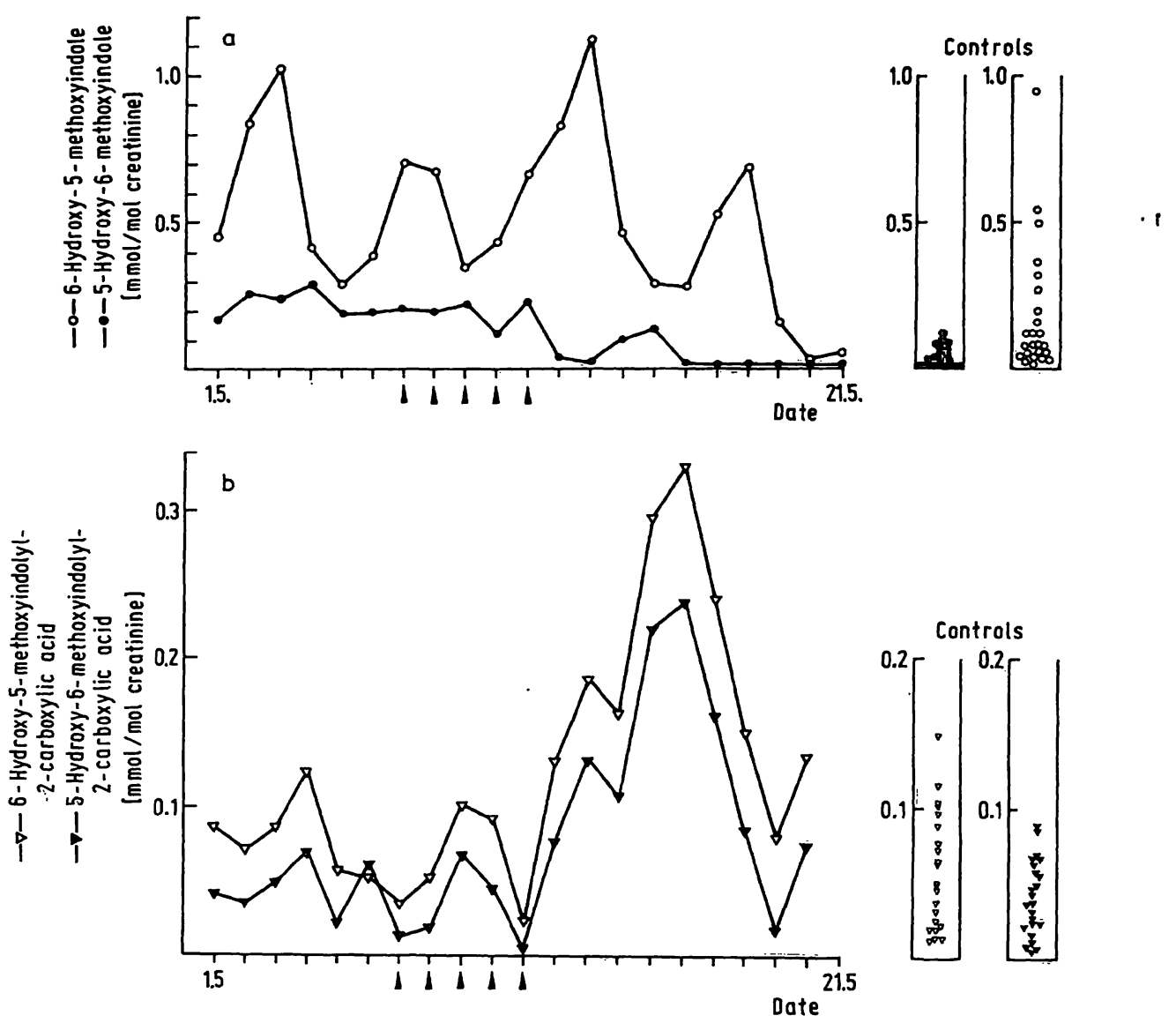

Fig. $5 \mathrm{a}-\mathrm{b}$. The urinary excretion of four eumelanin-related compounds by patient $\mathrm{S}$. $\mathrm{H}$., a woman aged 42 , admitted with diagnosis skin melanoma (leg). Treatment: surgical. In April 1982, generalization of the disease with high tumour burden (pulmonary metastases). The arrows indicate the days of the treatment.

In view of these problems, the determination of 5,6dihydroxyindole also does not seem to be suitable for routine purposes.

The recently discovered 5,6-dimethoxyindolyl-2-carboxylic acid (7) was present in normal urine in very low, sometimes undetectable amounts. Although this substance is interesting from the biochemical point of view, the small differences in its excretions in normal and melanotic urine (see fig. 2) make its determination less useful.

From the foregoing it can be seen that O-methylated indoles are apparently more suitable metabolites for routine measurements because of their relative stability. As shown in the follow-up curves of the melanoma patients, 5-hydroxy-6-methoxyindole consistently exhibited the highest differences between preand post-therapeutic stadia. It appears that this substance is the most sensitive indicator of increased eumelanin production for pigmented malignant melanoma.
5-Hydroxy-6-methoxyindolyl-2-carboxylic acid and 6-hydroxy-5-methoxyindolyl-2-carboxylic acid were found to be excreted in a pathological range, only if the excretion of the 5-hydroxy-6-methoxyindole was extremely elevated. In other cases, their excretion values were in the normal physiological range, so that they have limited value for the detection of the increased eumelanin production. Our measurements also showed a similar excretion of both isomeric acids, so it appears to be sufficient to measure only one of them.

Some patients exhibited a decrease of 5-hydroxy-6methoxyindole with a temporal overshoot of isomeric 5-hydroxy-6-methoxy- and 6-hydroxy-5-methoxyindolyl-2-carboxylic acid excretion after the treatment (see fig. 5). This fact raises the question of whether carboxylic and non-carboxylic eumelanin-related compounds share the same mode of generation, cell compartmentalization, and excretion from the organism. Further investigations aimed at interpreting the behaviour of each eumelanin-related metabolite will be necessary. 


\section{Walter de Gruyter ¿̨ Berlin-New York}

\section{Mobility and Recognition in Cell Biology}

\section{Proceedings of a FEBS Lecture Course held at the University of Konstanz, West Germany, September 6-10, 1982}

FEBS Lecture Course No. 82/09

Edited by $H$. Sund and C. Veeger

1983. $17 \mathrm{~cm} \times 24 \mathrm{~cm}$. XII, 586 pages.

Numerous illustrations. Hardcover.

DM 190,-; approx. US $\$ 86.50$

ISBN $311009536 \mathrm{X}$

\section{Principles of Recepterology}

Editor M. K. Agarwal

1983. $17 \mathrm{~cm} \times 24 \mathrm{~cm}$. VII, 677 pages. Numerous illustrations. Hardcover.

DM 220,-; approx. US $\$ 100.00$

ISBN 3110095580

\section{History of Clinical Chemistry}

Edited by J. Büttner

1983. $18 \mathrm{~cm} \times 26 \mathrm{~cm} .91$ pages with illustrations. Hardcover. DM 98,-; approx.

US \$44.75 ISBN 3110089122

\section{Modern Methods in Protein Chemistry}

\section{Review Articles}

following the Joint Meeting of the Nordic Biochemical Societies

Damp/Kiel, Germany,

September 27-29, 1982

Editor $H$. Tschesche

1983. $17 \mathrm{~cm} \times 24 \mathrm{~cm} . \mathrm{X}, 464$ pages.

Numerous illustrations. Hardcover.

DM 190,-; approx. US $\$ 86.50$

ISBN 3110095149

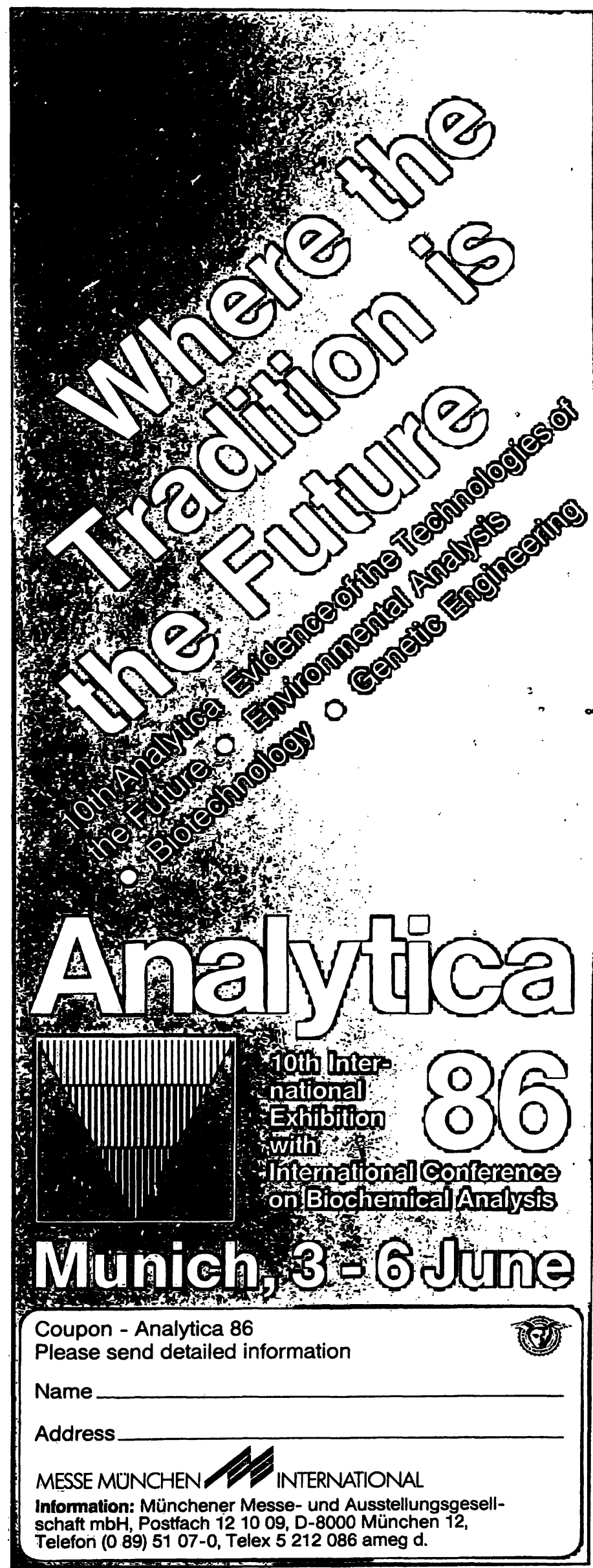




\section{SCHON GEWUSST?}

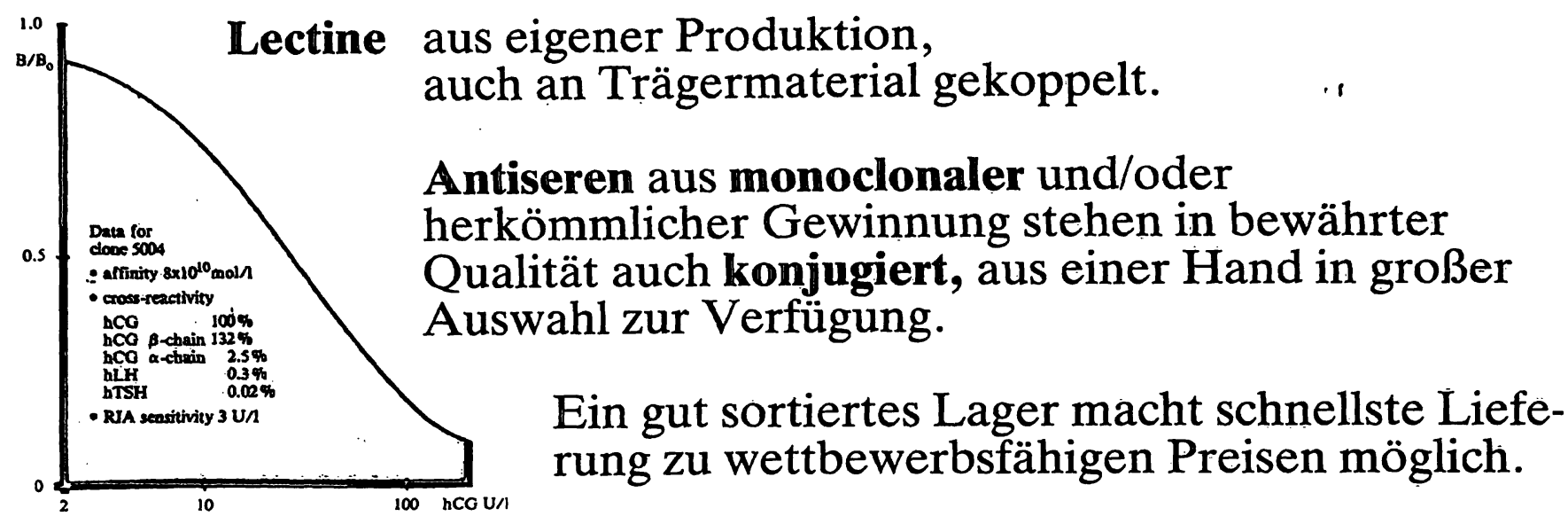

Bezug und weitere Information

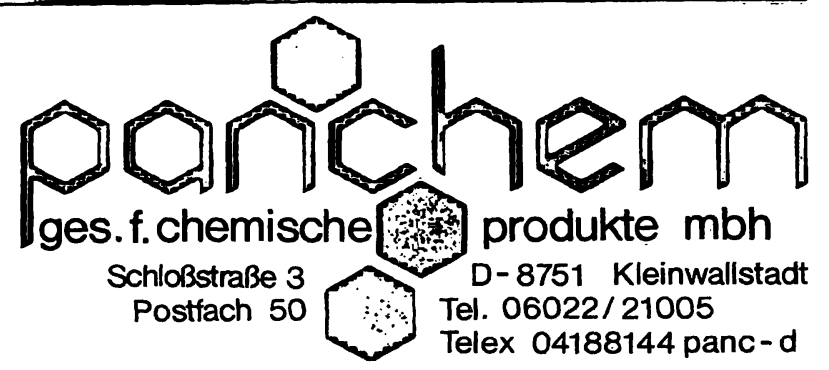

Trace Element

Analytical Chemistry in Medicine and Biology

Volume 3

Proceedings of the Third International

Workshop - Neuherberg,

Federal Republic of Germany, April 1984

\section{Editors P. Brätter, P. Schramel}

$1984.17 \mathrm{~cm} \times 24 \mathrm{~cm}$. XVI, 763 pages. Numerous illustrations.

Hardcover. DM 240,-; approx. US \$80.00 ISBN 3110098210

The proceedings contained in this volume are specifically concerned with new developments in the field of the essential trace elements selenium, zinc and manganese as well as with current problems in analysis, nutrition and medicine. The actual state of knowledge about other recently recognized essential trace elements also played a dominant role.

Price is subject to change without notice

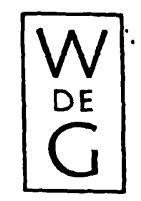

Walter de Gruyter - Berlin · New York

Verlag Walter de Gruyter \& Co., Genthiner Str.13, D-1000 Berlin 30, Tel.: (030) 26005-0, Telex 184027 Walter de Gruyter, Inc., 200 Saw Mill River Road, Hawthorne, N. Y. 10532, Tel.: (914) 747:0110, Telex 646677 
Since the eumelanin-related substances are specific metabolites of melanocytes, it is obvious that their excretion might be dependent on the amount of these melanin-forming cells as well as on their metabolic, namely melanogenic activity. That is why the decrease of the excretion of the eumelanin-related indoles after the treatment does not necessarily mean the reduction of the tumour mass, but may only indicate metabolic changes in the cellular metabolism of the melanocytes. The long-term follow-up may show whether these changes are transient or permanent, in other words, whether the treatment was effective. Correlation with clinical picture and repetitive measurements of the eumelanin-related compounds are therefore advisable.

\section{References}

1. Agrup, G., Agrup, P., Andersson, T., Hafström, L., Hansson, C., Jacobsson, S., Jönsson, P.-E., Rorsman, H., Rosengren, A.-M. \& Rosengren, E. (1979) Acta Dermatovenerol. (Stockh.) 59, 381 - 388 .

2. Graef, V. \& Paul, E. (1982) Br. J. Dermatol. 106, 53-57.

3. Jönsson, P.-E., Agrup, G., Arnbjörnsson, E., Hafström, L. O. \& Rorsman, H. (1980) Cancer 45, 245-248.

4. Duchon, J. \& Matous, B. (1967) Clin. Chim. Acta 16, 397-402.

5. Pavel, S., Muskiet, F. A. J., Budesinska, A. \& Duchon, J. (1981) Tumori 67, 325-332.

6. Pavel, S., Muskiet, F. A. J., Nagel, G. T. \& Duchon, J. (1981) Sborn. Lek. 83, 121-127.
In some cases, the high tumour load is not accompanied by an increased excretion of the eumelaninrelated metabolites (see fig. 5). This dissapointing fact can be explained by

(a) a low melanogenic activity of the tumour cells and/or by

(b) the existence of an alternative mode of excretion of the indolic metabolites (via bile).

A further investigation must be carried out to clarify the real cause of this discrepancy and to shed more light on the statement, made by Eppinger as early as 1910 (11), that so-called melanogenuria appears only after the development of liver metastases.

7. Pavel, S., Elzinga, H., Muskiet, F. A. J. \& Wolthers, B. G. (1983) Acta Dermatovenerol. (Stockh.) 63, 340-343.

8. Pavel, S. \& Muskiet, F. A. J. (1983) In: Human Tumour Markers; Biological Basis and Clinical Relevance (Nierburgs, H. E., Birkmayer, G. D. \& Klavins, J. V., eds.) Alan R. Liss Inc. (New York) pp. 311-316.

9. Pavel, S. \& Muskiet, F. A. J. (1983) J. Lab. Comp. Radiopharm. 20,101-110.

10. Pavel, S., Boverhof, R. \& Wolthers, B. G. (1984) J. Invest. Dermatol. 82, 577-579.

11. Eppinger, H. (1910) Biochem. Z. 28, 181.

\author{
Dr. S. Pavel \\ Department of Dermatology \\ Academic Medical Centre \\ University of Amsterdam \\ Meibergdreef 9 \\ NL-1105 AZ Amsterdam-Zuidoost
}




$$
i
$$

$\therefore$ 